\title{
A subjetividade como anomalia: estratégias médicas para lidar com os sintomas vagos e difusos em biomedicina
}

\author{
Carla Ribeiro Guedes \\ carla.rguedes@gmail.com \\ Tese de Doutorado em Saúde Coletiva \\ Instituto de Medicina Social/Universidade do Estado do Rio de Janeiro \\ Rio de Janeiro, 2007
}

O estudo busca compreender as estratégias utilizadas pelos médicos para lidar com pacientes que apresentam sintomas sem lesão orgânica ou causalidade reconhecida. Dificilmente enquadráveis nos diagnósticos possíveis em biomedicina, essas manifestações são frequentes na prática médica e recebem diferentes denominações, tais como 'funcionais', 'distúrbios neurovegetativos', 'somatizações', 'histeria', 'doenças psicossomáticas'. Com o objetivo de estabelecer uma discussão sobre a assistência médica aos sofredores de queixas consideradas vagas e difusas, utilizo como principal instrumento de análise a epistemologia, com destaque especial a Thomas Kuhn e às noções de paradigma e anomalia, e à contribuição de Ludwick Fleck com os conceitos de exceções das teorias e a tendência à persistência nos sistemas de ideias. Trabalho com a hipótese subjacente de que esses sofredores, ao apresentarem uma demanda que não apresenta lesão ou causalidade reconhecida, constituem uma anomalia - no sentido kuhniano - do paradigma biomédico. Em linhas gerais, Kuhn, em A estrutura das revoluções científicas, afirma que as anomalias são problemas que não estavam previstos, com os quais o cientista não se encontraria preparado para lidar. Assim como os cientistas, os médicos deparam com enigmas e fracassos em seu cotidiano, e um deles seria o conjunto de sofrimentos considerados vagos e difusos. A estratégia metodológica constou de revisão da literatura médica sobre o tema; observação etnográfica de consultas médicas num ambulatório de gastroenterologia de um hospital universitário; e de entrevistas semi-estruturadas com médicos de diferentes especialidades clínica-médica, reumatologia, dermatologia, cardiologia, gastroenterologia e medicina de família. A partir da análise do material empírico, concluo que a maioria dos médicos apresenta estratégias limitadas ao abordar os sofredores de sintomas indefinidos, as quais consistem em "dizer que o paciente não tem nada", "realizar encaminhamentos para profissionais de psicologia/psiquiatria" e "prescrever medicação - sintomáticos e tranquilizantes". Verifico que toda a gama de sintomas desacompanhada de lesão ou causalidade reconhecida aparece como anomalia ou exceção na biomedicina, uma vez que a prática médica possui poucos recursos teóricos e cognitivos para lidar com a subjetividade do adoecimento.

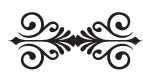

